\title{
Fine-scale ontogenetic shifts in settlement behaviour of mussels: changing responses to biofilm and conspecific settler presence in Mytilus galloprovincialis and Perna perna
}

\author{
Charles E. O. von der Meden*, Francesca Porri, Christopher D. McQuaid, \\ Katelyn Faulkner, James Robey
}

Coastal Research Group, Department of Zoology and Entomology, Rhodes University, PO Box 94, Grahamstown 6140, South Africa

\begin{abstract}
Larval settlement is critical to the establishment and maintenance of marine communities and is influenced by exogenous (bio-physical) and endogenous (behavioural or physiological) factors. Consequently, an understanding of settlement behaviour is specific to the bio-physical conditions and/or ontogenetic stage(s) examined. For intertidal organisms, the presence of settlementinducing or -inhibiting cues is well known, including various effects of biofilm and conspecifics. Studies of marine mussels, however, have incorporated little ontogenetic resolution and have almost exclusively been limited to investigation of larval-adult interactions. The present work examines behavioural responses of primary and secondary settlers of indigenous (Perna perna) and invasive (Mytilus galloprovincialis) mussels to biofilm and settler presence on artificial collectors at 2 sites in South Africa. Specifically testing for larva-settler and settler-settler interactions, this approach allowed for replication of site and species. It was hypothesised that biofilm and conspecific settlers would increase primary and secondary settlement of both species alike. Settler densities at one site were too low to detect treatment effects. At the other site, however, primary settlers of both species were significantly attracted to filmed rather than bare collectors (ANOVA, P. perna, $\mathrm{p}<0.01 ;$ M. galloprovincialis, $\mathrm{p}<0.05)$ and also avoided conspecific settlers, while secondary $P$. perna settlers preferred the combination of biofilm and conspecifics to other treatments (ANOVA, $\mathrm{p}<0.05)$. The findings represent an important ontogenetic shift in settlement behaviour with broad methodological and ecological implications, including possible explanations for natural patterns of habitat use by primary settlers, and the inhibition of switching between alternative stable states.
\end{abstract}

KEY WORDS: Perna perna $\cdot$ Mytilus galloprovincialis $\cdot$ Settlement cues $\cdot$ Behaviour $\cdot$ Biofilm · Conspecific attraction

Resale or republication not permitted without written consent of the publisher

\section{INTRODUCTION}

Settlement, the metamorphosis and attachment of larvae to benthic substrata, is a complex process (see Rodríguez et al. 1993 for review). Far from being strictly active or passive, settlement mode and behaviour are variable and can be influenced by endogenous and exogenous factors (Hadfield 1986). The former include inherent genetic, physiological, or developmental characteristics, often related to larval age and provisioning, and affect the 'readiness' of larvae to settle (e.g. Satuito et al. 1997, Marshall \& Keough 2003); the latter are usually physical or chemical environmental properties, including hydrodynamics and attributes of the substratum (e.g. Crisp \& Ryland 1960, Pernet et al. 2003, Dobretsov \& Wahl 2008). Consequently, variability of settlement behaviour may be as indicative of the biophysical conditions, spatial scales, or ontogenetic stages considered as they are of the variability in settlement habits of different study species. 
The role of cues, either as inducers (e.g. Keough \& Raimondi 1995, Zhao \& Qian 2002) or inhibitors (e.g. Maki et al. 1989, Dobretsov et al. 2006) of metamorphosis and settlement has been widely demonstrated for various benthic invertebrates. Such studies have highlighted the ability of biofilm and conspecifics to affect settlement and habitat selection. Despite some evidence for rapidly changing responses to cues between larvae differing in age by as little as 2 to $3 \mathrm{~d}$ (e.g. Marsden 1991), ontogenetic resolution in studies of settlement cues has been limited, focusing on primary settlers or on a single broad size-class. The current study presents a field investigation into the effects of biofilm and conspecific settlers on primary and secondary settlement behaviour of 2 mussel species. Although we use Bayne's (1964) terminology, the differentiation of primary and secondary settlers in the present study is purely size-based. Unlike in primary-secondary settlement studies (e.g. Bayne 1964, Eyster \& Pechenik 1988), we deal specifically with biofilm, not filamentous macroalgae, and cues from juvenile (larva-settler and settler-settler) conspecifics rather than adult conspecifics. Here we separate fully the effects of biofilm from those of physical (filamentous) substratum structure.

The presence of biological 'films' in the marine environment was first demonstrated in the 1930s, most notably by Zobell \& Allen (1935). Their work recorded the rapid ability of such films to form on submerged surfaces and is one of the earliest instances of an explicit link between microbial films and settlement. A biofilm is defined as a biological film that develops on submerged or intertidal surfaces, comprised mostly of bacteria, diatoms, flagellates and other unicellular organisms. Biofilmed surfaces, or specific components of such films, have been shown to increase settlement of various marine invertebrates (see Wieczorek \& Todd 1998 for review). Evidence of increased settlement also exists for pediveliger stage freshwater and marine mussel species, including Dreissena polymorpha (Kavouras \& Maki 2003), Mytilus galloprovincialis (Satuito et al. 1997, Bao et al. 2007), M. edulis galloprovincialis (Satuito et al. 1994) and $M$. edulis (Dobretsov 1999).

Similarly, chemical cues from conspecifics have been implicated in the gregarious settlement of multiple marine invertebrate phyla (reviewed by Meadows \& Campbell 1972, Pawlik 1992, Rodríguez et al. 1993). Much of what is known about conspecific attraction in mussels comes from work on freshwater species, particularly the zebra mussel Dreissena polymorpha. Most notably, greater settlement of $D$. polymorpha larvae (270 to $390 \mu \mathrm{m}$ ) has been shown to occur on live conspecific adults and dead shells than on other inanimate substrata with similar textural properties (Wainman et al. 1996). Likewise, the presence of adult conspecifics stimulated the attachment of larger individuals (>10 mm) of this species (Kobak 2001). In a similar laboratory study, contact between immature (>15 mm) freshwater mussels (Limnoperna fortunei) was shown to stimulate byssus secretion (Uryu et al. 1996). For marine species, increased recruitment of 'small' mussels (0 to $5 \mathrm{~mm}$ ) on collectors containing adult conspecifics has been shown for the ribbed mussel Geukensia demissa (Nielsen \& Franz 1995), while selection of adult conspecifics over a competitor species (Petersen 1984) and movement towards conspecific signal (de Vooys 2003) has been shown for Mytilus edulis.

Three tendencies are apparent in the literature concerning the effects of biofilm and conspecifics on mussels. (1) Studies focus either on primary settlers (e.g. pediveligers-Satuito et al. 1997, Dobretsov 1999, Bao et al. 2007) or examine single or a few broad sizeclasses (e.g. Davis \& Moreno 1995, Nielsen \& Franz 1995, Kobak 2001). While the former certainly aids in the identification of the initial patterns of settlement arising from cues and active habitat selection, the latter does not. This is because post-settlement processes such as settler mortality and relocation can interfere with the primary settlement pattern, a critical consideration for investigations of settlement behaviour (Bertness \& Grosholz 1985, Hadfield 1986, Huxham \& Richards 2003). (2) Only larva-adult (e.g. Nielsen \& Franz 1995, Wainman et al. 1996) or adult-adult conspecific interactions (e.g. de Vooys 2003) have been considered. There is, however, evidence of larva-settler interactions and attraction in settling polychaetes, barnacles and oysters (Hidu 1969, Marsden 1991, Clare et al. 1994), and it is possible that such inter-juvenile attraction occurs during mussel settlement too. This larva-settler attraction may be important, especially with respect to colonisation of new habitat. (3) Much of the work investigating the influence of biofilm and conspecific cues has been laboratory based (e.g. Crisp \& Ryland 1960, Uryu et al. 1996, Satuito et al. 1997), leaving some uncertainty about the applicability of the results under field conditions, where turbulence and dilution effects are likely to be important.

The present study addresses the gaps left by earlier studies, firstly by introducing fine-scale 'ontogenetic resolution' in the form of narrow size-classes separating primary and secondary settlers. Secondly, conspecific attraction is examined in terms of larva-settler interactions. Thirdly, all experiments were carried out in the field. The study therefore tests the effects of biofilm and conspecific settlers, separately and in combination, on subsequent primary and secondary settlement of co-existing indigenous (Perna perna) and 
introduced (Mytilus galloprovincialis) mussels in South Africa. It is hypothesised that both biofilm and conspecifics will increase settlement of all size-classes of these 2 species.

\section{MATERIALS AND METHODS}

For convenience the term 'conspecific' is used as shorthand for the presence of juvenile (primary and secondary settlers) mussels of either species, Mytilus galloprovincialis or Perna perna, while the term 'biofilm' refers to the whole assemblage of bacteria, diatoms and other microalgae that first colonise submerged substrata. The study species are referred to by genus only.

Experimental setup. The attraction of primary and secondary settlers to biofilm, conspecific settlers and a combination of the 2 was investigated on the south coast of South Africa. Two sites that can experience relatively high rates of settlement were chosen to allow for spatial replication of the experiment. Brenton-onSea $\left(34.07^{\circ} \mathrm{S}, 23.02^{\circ} \mathrm{E}\right)$ was sampled in April 2008, and the study was conducted the following month at Sedgefield $\left(34.03^{\circ} \mathrm{S}, 22.77^{\circ} \mathrm{E}\right)$. Larval settlement of Mytilus at Brenton-on-Sea during January and April was previously found to range from $<10$ to ca. 1000 settlers $\mathrm{d}^{-1}$ per collector; data for Perna at this site were equally variable, with settlement ranging from $<10$ to ca. 4250 settlers $\mathrm{d}^{-1}$ per collector (authors' unpubl. data). Comparative ranges for Sedgefield were lower, with neither species exceeding 1750 settlers $\mathrm{d}^{-1}$ per collector (authors' unpubl. data). We compared settle- ment over $24 \mathrm{~h}$ on pre-treated plastic collectors with that on untreated 'new' collectors. Collectors were plastic pot scourers commonly used as artificial settlement substrata in intertidal studies (e.g. Smith \& Rule 2002).

Treatment preparation. Three experimental treatments (biofilm [B], settler [S] and biofilm-settler [BS]) and one control treatment were developed over a $5 \mathrm{~d}$ preparatory period in the field, immediately prior to the experiment (see Fig. 1 for details). For each treatment, 10 collectors were deployed haphazardly within the low-shore mussel zone. This zone on the shore was chosen as it receives the highest levels of settlement of both study species (Porri et al. 2007). Each collector was attached to an eye-bolt screwed into the rock. (1) In the B treatment: collectors were enclosed in $15 \times$ $15 \mathrm{~cm}$ bags of $200 \mu \mathrm{m}$ mesh, which allowed bacteria and the majority of diatoms $\left(<200 \mu m_{i}\right.$ Azam et al. 1983) to establish biofilm, while excluding competent pediveliger larvae (ca. $270 \mu \mathrm{m}$; Bownes 2005). (2) In the S treatment: collectors were used to gather primary and secondary settlers over the first $4 \mathrm{~d}$ of the preparatory period. At the field laboratory on Day 5, settlers from each collector were washed off and 'seeded' onto a bare collector in order to exclude biofilm. Once seeded, each collector was placed into a $250 \mathrm{ml}$ jar and maintained in aerated seawater for the remaining $24 \mathrm{~h}$ of the preparatory period. This allowed settlers to attach fully to the collector. (3) In the BS treatment: natural settlement and biofilm development was allowed to occur on these collectors during the $5 \mathrm{~d}$ preparatory period. In addition, a control treatment was prepared, biofilm-settlers shaded $\left(\mathrm{BS}_{\text {shaded }}\right)$ :

\begin{tabular}{|c|c|c|}
\hline TREATMENT PREPARATION (FIELD, Day 1 to 5) & 24 h STAINING (LABORATORY, Day 6) & 24 h EXPERIMENT (FIELD, Day 7) \\
\hline $\begin{array}{l}\text { - } 10 \text { x pads sealed in } 200 \mu \mathrm{m} \text { mesh bag } \\
\text { - } 10 \text { x pads exposed } \\
\text { - } 10 \text { x pads exposed } \\
\text { (to gather settlers for later seeding) } \\
\text { CONTROL TREATMENT PREPARATION } \\
\text { - } 10 \text { x pads partially exposed } \\
\text { (top half covered by mesh) }\end{array}$ & 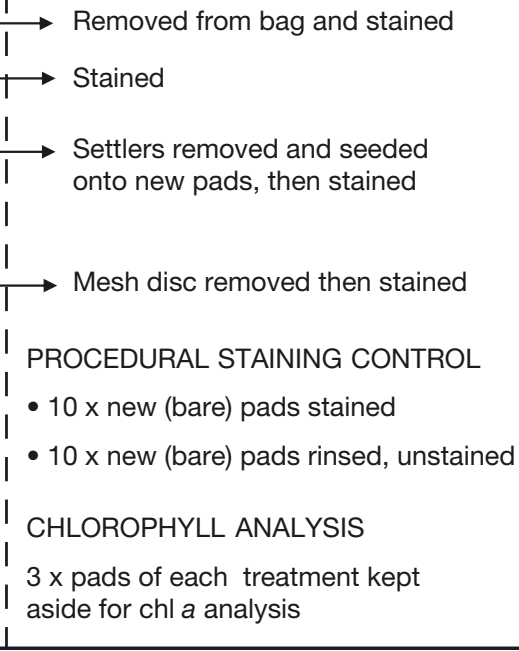 & $\begin{array}{l}\text { I = Biofilm }(\mathrm{B}) \\
\text { I = Biofilm \& settler }(\mathrm{BS}) \\
\text { I = Settler }(\mathrm{S}) \\
\text { I } \\
\text { I = Biofilm \& settler shaded }\left(\mathrm{BS}_{\text {shaded }}\right) \\
\text { I } \\
\text { I = New Unwashed stained }\left(\mathrm{NUW}_{\text {stained }}\right) \\
\text { I = New Washed unstained }\left(\mathrm{NW}_{\text {unstained }}\right) \\
\text { I } \\
\text { I }\end{array}$ \\
\hline
\end{tabular}

Fig. 1. Diagram of the experimental setup and treatments. Moving from left to right are details of the treatment preparation, staining and experimental deployment 
$200 \mu \mathrm{m}$ mesh discs of $10 \mathrm{~cm}$ diameter were sewn onto the top of collectors to control for possible effects of shading created by the mesh bags in the biofilm treatment. This partial covering of the collectors allowed settlement and maintained biofilm development at levels comparable to those found on the 'bagged' biofilm treatment collectors. Although the quantity of biofilm could not be directly controlled or standardised across all preparatory treatments, 3 of the 10 collectors in each of the above treatments were haphazardly designated as 'chlorophyll testers'. These collectors were kept aside at the end of the preparatory period, wrapped in aluminium foil and immediately frozen to allow quantification of biofilm in bagged (B), shaded $\left(\mathrm{BS}_{\text {shaded }}\right)$ and unshaded (BS) treatments.

Settler staining. On Day 5 of the preparatory period, all treatments, except the $\mathrm{S}$ treatment, which had already been collected on Day 4, were removed to the field laboratory where each collector was placed into a $250 \mathrm{ml}$ plastic jar. In order to mark settlers, each jar was filled with a $200 \mathrm{mg} \mathrm{l}^{-1}$ solution of calcein in seawater and aerated for $24 \mathrm{~h}$ to allow maximum uptake of the stain by the settlers (see Eads \& Layzer 2002). This fluorescent staining technique has been shown to mark safely calcium carbonate shelled organisms such as abalone, gastropods and mussels (Day et al. 1995, Kaehler \& McQuaid 1999, Moran 2000, Eads \& Layzer 2002). Lastly, 2 additional control treatments were created using new collectors: (1) the new unwashed stained ( $\left.\mathrm{NUW}_{\text {stained }}\right)$ treatment, for which 10 new collectors were submerged in calcein solution for $24 \mathrm{~h}$ and (2) the new washed unstained $\left(\mathrm{NW}_{\text {unstained }}\right)$, for which 10 new collectors were simply rinsed in fresh water and left to dry. This setup enabled comparison of settlement between stained and unstained collectors, allowing identification of any effects of the calcein stain on settlement in relation to stained settlers and collectors.

The 24 h experiment. On Day 6, all prepared collectors (except those kept aside for chlorophyll a [chl a] analysis) were re-deployed haphazardly on the shore without their various preparatory treatment coverings. All treatments and controls were left for $24 \mathrm{~h}$, then retrieved and individually stored in $70 \%$ ethanol for later processing.

Laboratory procedures. Each collector, apart from those kept for chlorophyll analysis, was thoroughly rinsed in freshwater, and a $75 \mu \mathrm{m}$ sieve was used to retain all mussel settlers. Mytilus and Perna settlers were then identified using morphological features (Bownes et al. 2008), measured and grouped into 4 size-classes and counted, using a stereo microscope at $25 \times$ magnification. These size-classes were based on growth rates estimated by Bownes (2005), identifying primary settlers that must have settled during the $24 \mathrm{~h}$ deployment $(<360 \mu \mathrm{m})$, those that settled at the start of the preliminary deployment and had thus undergone growth for $5 \mathrm{~d}$ before the experimental deployment at either low (360 to $440 \mu \mathrm{m}$ ) or high (441 to $590 \mu \mathrm{m}$ ) growth rates and, finally, secondary settlers that were too large to have settled and grown in situ during either phase of the experiment and that must have relocated from elsewhere ( $>590 \mu \mathrm{m})$.

Treatments that could have contained stained settlers (i.e. $\mathrm{S}, \mathrm{BS}$ and $\mathrm{BS}_{\text {shaded }}$ ) were examined using an Olympus fluorescence microscope with a 460 to $490 \mathrm{~nm}$ excitation filter (U-MWIB Cube) as described by Kaehler \& McQuaid (1999). The number of calceinstained individuals in each size-class was recorded. Subtraction of the number of stained settlers from total settlers gave the number of (unstained) new settlers arriving on the collectors over the $24 \mathrm{~h}$ experiment. The number of settlers in each of the remaining treatments, i.e. those not containing settlers prior to the experiment $\left(\mathrm{B}, \mathrm{NW}_{\text {unstained }}\right.$ and $\left.\mathrm{NUW}_{\text {stained }}\right)$ directly indicated the number of settlers arriving over the $24 \mathrm{~h}$ experiment. The rate of settlement over $24 \mathrm{~h}$ could then be compared across treatments.

Chl $\boldsymbol{a}$ analysis. Since biofilms include diatoms and other microalgae, the concentration of chl $a$ is used as an indicator of quantity or biomass of epilithic biofilm (Thompson et al. 1999). Chlorophyll extraction was done using room temperature analytical grade (99\%) methanol (see Thompson et al. 1999). The surface area of each collector was calculated using the weight of low viscosity 'baby' oil adhering to them (Mapstone et al. 1984). This allowed the concentration of chl $a$ to be expressed as $\mu \mathrm{g} \mathrm{cm}^{-2}$ and compared among Treatments $\mathrm{B}, \mathrm{BS}$ and $\mathrm{BS}_{\text {shaded. }}$ Chlorophyll analysis was undertaken only on samples from the experiment at Brenton-on-Sea.

Statistical analyses. Separate 2-way ANOVA analyses were run using the factors Site (random, 2 levels) and Treatment (fixed, 6 levels, $\mathrm{n}=6$ ), comparing the number of settlers across Treatments and Sites, for each species/size-class combination. Significant results were further examined using Student-Newman-Keuls (SNK) post hoc tests. Since data for both species and all size-classes came from single collectors, correlations of settlement between species and between size-classes within species were checked to determine the independence of the data. This involved examining the correlation of primary settlement of Perna (across all Treatments and Sites) with that of Mytilus, and repeating this with the secondary settlement data. Size-class correlations were done, examining all possible combinations of size-class within each species. For example, the correlations of primary Perna settlers (Size-class 1) with Size-classes 2, 3 and 4 were individually examined to test whether the 
number of settlers in Classes 2, 3, or 4 were dependent on the number of Class 1 settlers.

Based on these correlations, separate ANOVAs were done for each species and size-class, using only the smallest (primary settler) and largest (secondary settler) classes. Equivalent correlations for the Sedgefield site were more variable, but in the interests of using an analysis that included site as a factor, the corresponding size-classes were used for analysis of Sedgefield data.

This brought the total number of analyses to 4 (2 size-classes for each of 2 species). Using the ShapiroWilks test, none of the data were found to be normally distributed ( $p<0.001$ in all cases). The homogeneity of variances was checked in each ANOVA, and none were homogeneous (Cochran's $C$-test, $\mathrm{p}<0.05$ in all cases). Transformation of the data did not improve heteroscedasticity; hence, all analyses were done on untransformed data. This approach was considered valid due to the large overall sample size drawn from 2 sites, including 6 treatments with 6 replicates each (Underwood 1997).

A 1-way ANOVA (fixed, 3 levels, $n=3$ ) was performed to determine whether chl a concentrations differed between the bagged (B), shaded $\left(\mathrm{BS}_{\text {shaded }}\right)$ and unshaded (BS) treatments at Brenton-on-Sea. This analysis was done on untransformed data, as variances were homogenous (Cochran's $C=0.78$, df $=2, \mathrm{p}=0.16$; Zar 1999).

The effects of biofilm and conspecific attraction were then quantified by examining differences in mean settlement between the relevant (significant post hoc

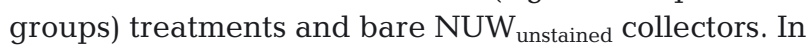
this way an enhancement factor was calculated for primary and secondary settlement, determining the factor by which mean settlement was greater on the statistically significant treatment collectors than on the bare collectors, using the equation:

Enhancement factor $=\frac{\text { Mean settlers on treatment }}{\text { Mean settlers on NUW }}$

These calculations were only done on data from Brenton-on-Sea, due to the low settlement at Sedgefield.

\section{RESULTS}

\section{Procedural results}

Overall, numbers of primary $(<360 \mu \mathrm{m})$ Perna settlers correlated with those of Mytilus ( $\mathrm{r}=0.66, \mathrm{n}=72$, $\mathrm{p}<0.05)$, showing that species data were not independent. No overall correlation was found between large $(>590 \mu \mathrm{m})$ secondary settlers of Perna and Mytilus ( $\mathrm{r}=-0.0075, \mathrm{n}=72, \mathrm{p}>0.05$ ). Similarly, no correlation was found between numbers of primary and large secondary settlers of Perna $(\mathrm{r}=0.248, \mathrm{n}=$ $72, \mathrm{p}>0.05$ ) or Mytilus ( $\mathrm{r}=-0.166, \mathrm{n}=72, \mathrm{p}>0.05$ ). The size-class data were therefore considered independent, but primary settlement data for the 2 species were dependent.

Chl a level did not differ significantly between the bagged (B), shaded ( $\left.\mathrm{BS}_{\text {shaded }}\right)$ and unshaded (BS) treatments $\left(F_{2,6}=0.5, \mathrm{p}>0.05\right)$, suggesting comparable biofilm development. Similarly, the ANOVAs and post hoc tests on primary and secondary settlement data confirmed that the calcein staining technique did not affect settlement of either species, since no significant differences existed between $\mathrm{NUW}_{\text {stained }}$ and $\mathrm{NW}_{\text {unstained }}$ collectors.

\section{Primary settlement}

Statistical analysis of primary settlement data revealed significant treatment by site interactions for both species (Perna: $F_{5,60}=5.51, \mathrm{p}<0.001$, Table 1a; Mytilus: $F_{5,60}=$ 5.92; $\mathrm{p}<0.001$, Table $1 \mathrm{~b})$. Significantly greater settlement of both species occurred in the $\mathrm{BS}_{\text {shaded }}$ and $\mathrm{B}$ treatments at Brenton-on-Sea than in any other treatments, including the BS treatment (SNK tests; Table 1a,b). Here, the $\mathrm{BS}_{\text {shaded }}$ treatment received the highest number of settlers of each species, followed by the B treatment (Fig. 2a,b). Settlement in the S and BS treatments at Brenton-on-Sea were thus statistically comparable to the biologically 'bare' treatments ( $\left.\mathrm{NUW}_{\text {stained }} \mathrm{NW}_{\text {unstained }}\right)$, which did not have biofilm or a settler presence and received the lowest numbers of settlers.

No treatment effects occurred at Sedgefield (Table $1 \mathrm{a}-\mathrm{d})$, where settlement was far lower and speciesspecific patterns across treatments less consistent than at Brenton-on-Sea (mean settlement in all treatments $\leq 1.5$ settlers; Fig. 2c,d). Although not significant, it can be seen that the pattern of higher settlement in the B treatment than in the other treatments did occur for Mytilus at Sedgefield. While the greatest settlement of Perna at this site occurred in the $\mathrm{BS}_{\text {shaded }}$ treatment, this was followed by the $\mathrm{NW}_{\text {unstained }}$ treatment rather than the B treatment (Fig. 2c) unlike the pattern at Brenton-on-Sea. Again, low levels of settlement may explain these differences in pattern between sites.

\section{Secondary settlement}

Contrary to our predictions, secondary settlement was not significantly enhanced by either biofilm or conspecific presence on their own at either site. Rather, 
Table 1. Perna perna and Mytilus galloprovincialis. Two-way ANOVA and Student-Newman-Keuls (SNK) post hoc test results for primary settlement and secondary settlement data. $\mathrm{BS}_{\text {shaded }}$ : biofilm-settler shaded treatment; B: biofilm treatment; BS: biofilm-settler treatment

\begin{tabular}{|c|c|c|c|c|}
\hline Source & df & MS & $F$ & $\mathrm{p}$ \\
\hline \multicolumn{5}{|c|}{ (a) P. perna (primary settlement) } \\
\hline Treatment & 5 & 19.76 & 1.75 & $>0.05$ \\
\hline Site & 1 & 80.22 & 7.11 & $<0.05$ \\
\hline Treatment $\times$ Site & 5 & 11.29 & 5.51 & $<0.001$ \\
\hline Error & 60 & 2.05 & & \\
\hline \multicolumn{5}{|c|}{$\mathrm{SNK} \mathrm{BS}_{\text {shaded }}>\mathrm{B}>$ all other treatment site combinations (for Brenton-on-Sea) } \\
\hline \multicolumn{5}{|c|}{ (b) M. galloprovincialis (primary settlement) } \\
\hline Treatment & 5 & 9.01 & 1.07 & $>0.05$ \\
\hline Site & 1 & 13.35 & 1.59 & $>0.05$ \\
\hline Treatment $\times$ Site & 5 & 8.41 & 5.93 & $<0.001$ \\
\hline Error & 60 & 1.42 & & \\
\hline \multicolumn{5}{|c|}{$\mathrm{SNK} \mathrm{BS}_{\text {shaded }}>\mathrm{B}>$ all other treatment site combinations (for Brenton-on-Sea) } \\
\hline \multicolumn{5}{|c|}{ (c) P. perna (secondary settlement) } \\
\hline Treatment & 5 & 1647.81 & 2.62 & $<0.001$ \\
\hline Site & 1 & 1503.35 & 2.39 & $<0.01$ \\
\hline Treatment $\times$ Site & 5 & 629.41 & 4.68 & $<0.01$ \\
\hline Error & 60 & 134.50 & & \\
\hline \multicolumn{5}{|c|}{ SNK BS > all other treatment site combinations (for Brenton-on-Sea) } \\
\hline \multicolumn{5}{|c|}{ (d) M. galloprovincialis (secondary settlement) } \\
\hline Treatment & 5 & 7.01 & 0.88 & $>0.05$ \\
\hline Site & 1 & 342.34 & 42.72 & $<0.01$ \\
\hline Treatment $\times$ Site & 5 & 8.01 & 1.37 & $>0.05$ \\
\hline Error & 60 & 5.85 & & \\
\hline
\end{tabular}

a significant treatment by site interaction was indentified for Perna at Brenton-on-Sea, with SNK tests showing that, unlike primary settlers, secondary settlement was significantly greater in the combined BS treatment than other treatment by site combinations (Perna: $F_{5,60}=4.68, \mathrm{p}<0.01$, Table 1c; Mytilus: $F_{5,60}=1.37, \mathrm{p}>$ 0.05, Table 1d; Fig. 3a). While no interaction or treatment effects were found for Mytilus, a site effect was identified, with Sedgefield receiving significantly more Mytilus settlement than Brenton-on-Sea $\left(F_{5,60}=\right.$ 42.72, p < 0.01, Table 1d). Although only significant for Perna at Brenton-on-Sea, secondary settlement in the BS treatment was generally elevated relative to other treatments for both species at both sites (Fig. 3a to d).

\section{Discredited shading control}

In terms of primary settlement, the $\mathrm{BS}_{\text {shaded }}$ treatment had significantly more settlers than any other treatment in all cases except for Mytilus at Sedgefield. The pattern was, however, less commonly seen in the secondary settlement data. If mean primary settlement of the $\mathrm{BS}_{\text {shaded }}$ treatment is compared to that of the $\mathrm{BS}$ treatment, an identical treatment apart from the mesh covering half of the collector, it can be seen that the shaded treatment accumulated well over double the number of settlers at both sites (Fig. 2). The $\mathrm{BS}_{\text {shaded }}$ treatment is therefore excluded from interpretation of settlement results (see 'Discussion' for explanation).

In synthesis, with the discredited $\mathrm{BS}_{\text {shaded }}$ treatment removed, the B treatment at Brenton-on-Sea attracted significantly higher primary settlement over $24 \mathrm{~h}$ than did the 4 other treatments $\left(\mathrm{NUW}_{\text {stained, }} \mathrm{NW}_{\text {unstained, }} \mathrm{BS}\right.$ and S), all of which had similar numbers of settlers. Therefore, the presence of settlers in the $\mathrm{S}$ and BS treatments did not induce higher primary settlement than occurred on bare collectors. Since the B and BS treatments were identical, apart from the presence of conspecifics, the statistical difference between these treatments indicates avoidance of conspecifics by primary settlers.

Using the same exclusion (of the $\mathrm{BS}_{\text {shaded }}$ treatment) for secondary settler data, secondary settlement was generally greater in the BS treatment at both sites (with the exception of Mytilus at Brenton-on-Sea). This attraction to the BS treatment was, however, only statistically significant at Brenton-on-Sea for Perna. Thus, enhanced secondary settlement required the combination of biofilm and conspecific presence.

As Figs. 2 \& 3 show, primary settlement of Perna at Brenton-on-Sea increased 3.8-fold from a mean of 1.17 on bare collectors to 4.5 on B treatment collectors, while Mytilus increased 18.6-fold between bare and biofilmed collectors. Mean secondary settlement of Perna at Brenton-on-Sea increased by 6.6-fold from 8.3 on the bare collectors to 55 on BS treatment collectors. With no significant treatment effects on secondary settlement for Mytilus, an enhancement factor was not calculated.

\section{DISCUSSION}

In testing for the effects of biofilm and conspecific cues on primary and secondary settler behaviour, we predicted that both biofilm and conspecific presence would have ubiquitous positive effects on settlement in general. Contrary to this hypothesis, however, the most striking results of the present study were the dis- 
(a) Perna (Brenton-on-Sea)
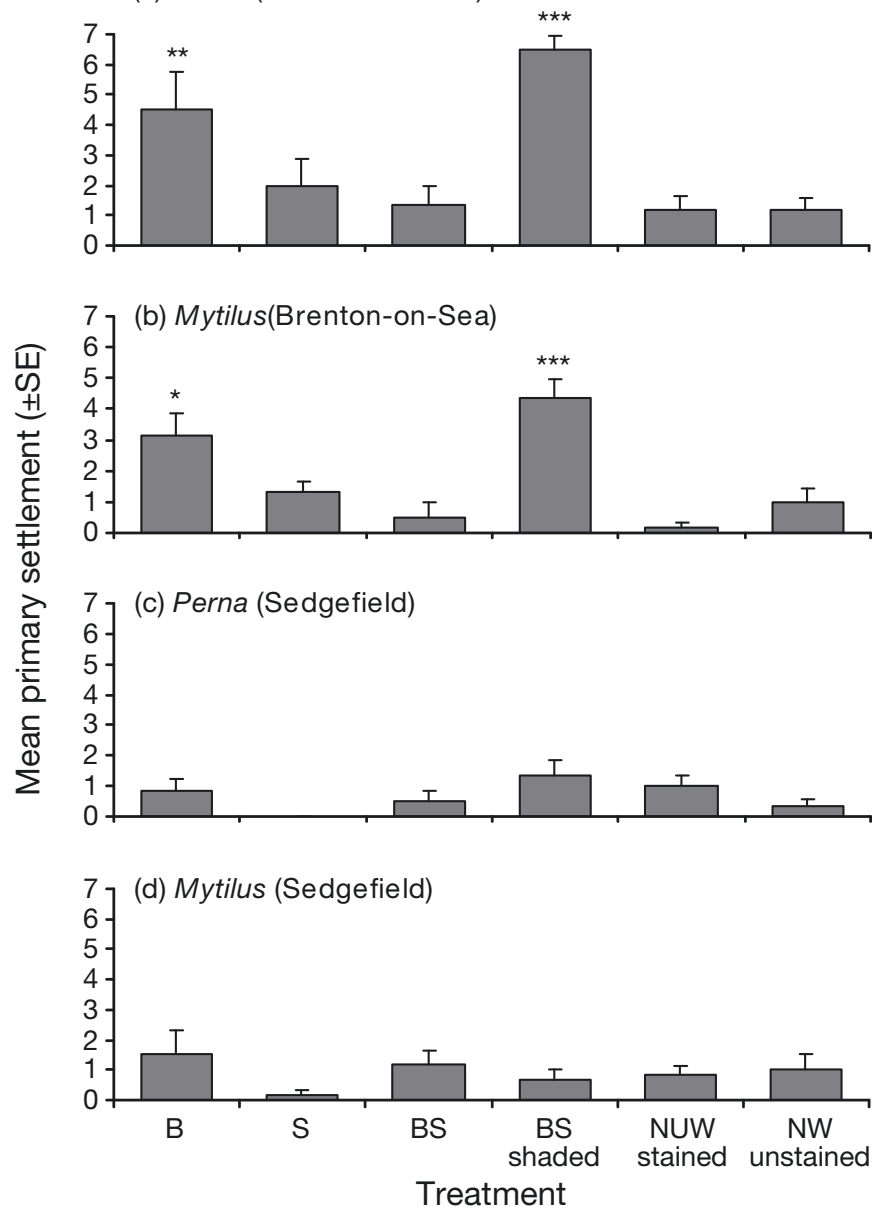

Fig. 2. Perna perna and Mytilus galloprovincialis. Mean primary settlement $(+\mathrm{SE})$ in the 6 treatments over the $24 \mathrm{~h}$ experimental period at 2 sites: $(\mathrm{a}, \mathrm{b})$ Brenton-on-Sea and $(\mathrm{c}, \mathrm{d})$ Sedgefield. Treatments: $\mathrm{B}=$ biofilm with settlers excluded; $\mathrm{S}=$ settlers seeded onto bare collectors; BS = natural biofilm and settler presence; $\mathrm{NW}_{\text {unstained }}=$ bare, unstained washed collectors; controls: $\mathrm{BS}_{\text {shaded }}=$ biofilm and settler presence with partial mesh shading (shading control); $\mathrm{NUW}_{\text {stained }}=$ bare, stained and unwashed collectors (staining control). Student-Newman-

Keuls results are indicated $\left({ }^{*}<0.05,{ }^{* *}<0.01,{ }^{* * *}<0.001\right)$

tinctly different responses of primary and secondary settlers to the settlement cues. In essence, primary settlement of both species was significantly greater on collectors bearing biofilm (B) than on bare collectors $\left(\mathrm{NUW}_{\text {stained, }} \mathrm{NW}_{\text {unstained }}\right)$ and treatments with an initial settler presence (S and BS), even if the latter included biofilm (see Fig. 1 for summary of treatment details).

More than simply indicating attraction to collectors with biofilm, comparison of settlement rates in B and BS treatments suggested active avoidance of conspecifics by primary settlers. The fact that the $\mathrm{S}$ treatment at Sedgefield received the lowest number of primary settlers for both species supports this idea. In (a) Perna (Brenton-on-Sea)

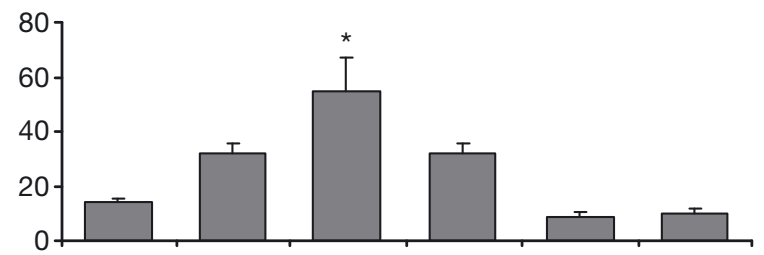

(b) Mytilus (Brenton-on-Sea)

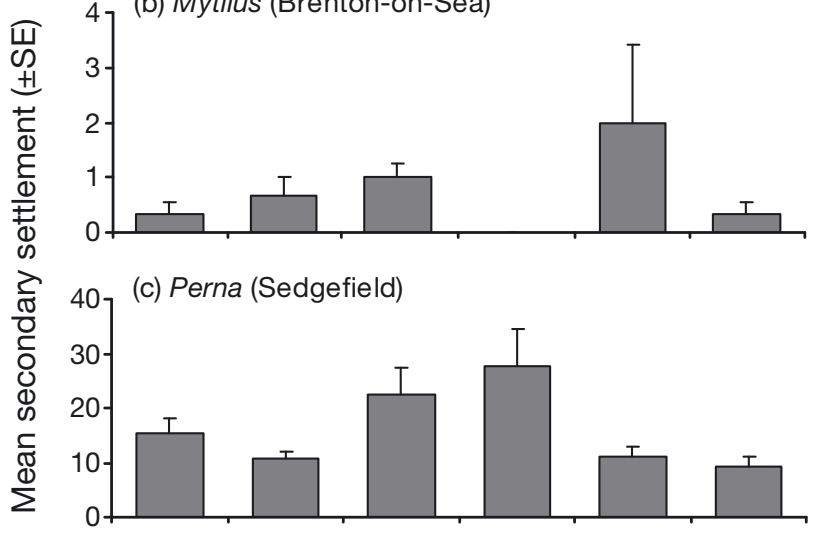

10 (d) Mytilus (Sedgefield)

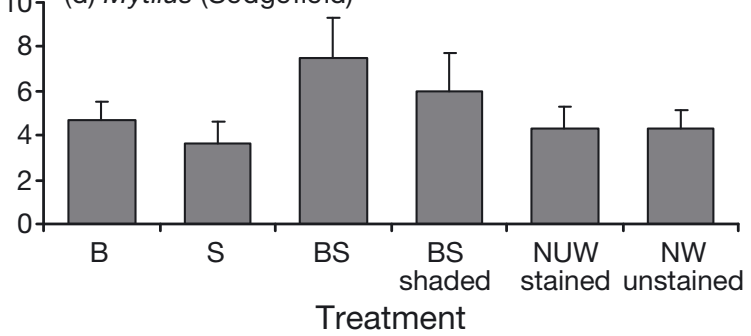

Fig. 3. Perna perna and Mytilus galloprovincialis. Mean secondary settlement $(+\mathrm{SE})$ in the 6 treatments over the $24 \mathrm{~h}$ experimental period at 2 sites: $(a, b)$ Brenton-on-Sea and (c,d) Sedgefield. Treatments: $\mathrm{B}=$ biofilm with settlers excluded $\mathrm{S}=$ settlers seeded onto bare collectors; $\mathrm{BS}=$ natural biofilm and settler presence; $\mathrm{NW}_{\text {unstained }}=$ bare, unstained and washed collectors. Controls: $\mathrm{BS}_{\text {shaded }}=$ biofilm and settler presence with partial mesh shading (shading control); $\mathrm{NUW}_{\text {stained }}=$ bare, stained and unwashed collectors (staining control). Note: $y$-axis scales not equal. Student-Newman-Keuls results are indicated $\left({ }^{*}<0.05\right)$

contrast, secondary settlement (of Perna) was greatest in treatments with a settler presence, especially the BS treatment. At Brenton-on-Sea, the S treatment also received high numbers of secondary Perna settlers, but this pattern was not seen at Sedgefield for either species. Thus, it seems that conspecific settlers can have an attractant effect on secondary settlers, and that this attraction is enhanced by biofilm. Importantly, the lack of significant treatment effects on primary and secondary settlement at Sedgefield demonstrates that the effects of biofilm and conspecifics may not always occur or may not always be detectable, especially if settlement rates are low. 


\section{Reasoning for exclusion of shading control}

During the preparatory period the presence of mesh discs in the $\mathrm{BS}_{\text {shaded }}$ treatment could have had 2 effects: (1) shading and (2) netting or physically trapping settlers. Since larvae, including Mytilus edulis pediveligers, may respond photonegatively to light intensity at settlement (e.g. Bayne 1964, Svane \& Dolmer 1995) both the shading and netting effects may potentially have increased settlement of conspecifics over the preparatory period. Given that no significant difference in chl a was found among shaded, bagged and unshaded treatments, however, it is unlikely that light intensity was significantly altered by the mesh discs. Rather, a strong 'netting effect' is plausible, since the collectors were able to orientate themselves slightly with water movement creating a mesh 'net', resulting in visible abnormal accumulations of sediment and organic detritus, and presumably also of settlers. Although the mesh discs were not present during the $24 \mathrm{~h}$ experiment itself, these abnormal accumulations, particularly of conspecifics, seem to have had strong effects on subsequent settlement. Due to the uncertainty of these effects, the $\mathrm{BS}_{\text {shaded }}$ treatment is excluded from the discussion and interpretation of settlement results.

\section{Mechanisms for larva-substratum and larva-settler interactions}

Mechanisms for interactions among larvae, settlement-site substratum and conspecifics are variable both within and among species (see Hadfield 1986, Pawlik 1992, Qian 1999 for review). While some evidence suggests chemosensory detection of conspecific- and biofilm-related cues in mussels (Dobretsov 1999, Kobak 2001, de Vooys 2003), studies on other taxa have shown that physical contact is required for cue detection (e.g. Wilson 1968, Pawlik 1986, Harder et al. 2002). Chemical and tactile detection are, however, not mutually exclusive as they may be used at different times during the settlement process (e.g. Chia \& Koss 1988). Pawlik (1992) reviewed the notion that cues act in a hierarchical sequence in which particular cues indicate broad suitability of an area of habitat, followed by site-specific cues that induce settlement and metamorphosis at that location. This sequential influence of different settlement cues seems a likely explanation for the changing settlement behaviour recorded in the current study. With specific regard to mussels, the action of waterborne, biofilm-associated cue(s) that induce larval crawling behaviour has been identified (Satuito et al. 1995, Dobretsov 1999), along with the subsequent presence, and separate effect, of a surface- bound cue that induces metamorphosis (Bao et al. 2007). The high degree of specificity with which these biofilm cues act on larvae and primary settlers provides a plausible mechanism by which primary settlement would be increased in the B treatment only, relative to bare or $\mathrm{S}$ treatments in the present study.

In terms of conspecific cues, most studies reporting conspecific effects on young mussels have not separated effects on primary settlers from those affecting older post-larvae (e.g. Nielsen \& Franz 1995, de Vooys 2003, but see Wainman et al. 1996) and therefore do not necessarily contradict the lack of conspecific effects on primary settlers observed in the current study. It is possible that biofilm cues continue to affect secondary settlers in a similar way to primary settlers and induce searching behaviour. The synergistic effect of increased searching behaviour and attraction to conspecific settlers may then explain the greater secondary settlement in the combined BS treatment over the $\mathrm{S}$ treatment.

Although field bioassays limit control over standardisation of larval supply and the presence of nonstudy species, they allow confirmation of cue detection and larval responses under natural conditions. The results of the present study provide field evidence for the sequential action and ontogenetic specificity of settlement cues and their detection, previously demonstrated only under laboratory conditions. While it is possible that the biofouling communities on collectors may have differed between sites or even treatments, only the $\mathrm{BS}$ and the $\mathrm{BS}_{\text {shaded }}$ treatments were exposed to colonisation during the preparatory period, and all treatments were equally exposed during the experiment itself. This limited exposure should mean little, or at least universal interference from other organisms.

\section{Ontogenetic shifts as evolutionary strategy}

The dichotomous findings of the present study demonstrate the importance of including fine-scale ontogenetic resolution into settlement studies. Ontogenetic niche and habitat shifts are known to occur in juvenile aquatic organisms such as bluegill sunfish and largemouth bass, and may broadly influence population dynamics (Werner \& Hall 1988, Olson 1996). Moreover, behavioural shifts, in the form of changing post-settlement responses to conspecific adults, have recently been shown to occur in large recruits (9 to $10 \mathrm{~mm}$ ) of one of our study species, Perna perna (Erlandsson et al. 2008).

Logically, the conspecific avoidance by primary settlers and conspecific attraction among secondary settlers highlighted in the present study could be 
explained in terms of evolutionary responses to larviphagy and/or competition. Initially, small (mostly primary) settlers should be expected to avoid conspecifics so as to lower the risk of larviphagy by adults (e.g. Porri et al. 2008). Although the maximum size refuge from larviphagy in bivalves may be quite large ( $\pm 600 \mu \mathrm{m}$ for Mytilus edulis; Lehane \& Davenport 2004), the risk of ingestion lessens with increasing settler size, with the majority of ingested larvae being around $400 \mu \mathrm{m}$ or less (Lehane \& Davenport 2004, Porri et al. 2008). Consequently, larvae $>400 \mu \mathrm{m}$ should, on average, be less susceptible to ingestion by adult conspecifics. This 'cut-off' size loosely matches the size dividing primary and secondary settlers (ca. $360 \mu \mathrm{m}$ ) and, therefore, supports the notion that decreasing selection pressure against conspecific attraction should accompany growth from primary settler size to secondary settler size. In addition, the size and age-class separation afforded by differential settlement behaviour of primary and secondary settlers may result in reduced intraspecific competition for food due to resource partitioning of sorts (Bertness \& Grosholz 1985). Either way, the settlement behaviour recorded in the present study means that juvenile mussel populations benefit from aggregated distributions at the appropriate times while reducing competition during this vulnerable period.

\section{Generality and magnitude of cue effects}

The degree to which settlement increased in response to biofilm (primary settlers of both species) and to conspecific presence (secondary Perna settlers) compares well with other studies. For example, Satuito et al. (1997) showed that $70 \%$ of competent Mytilus galloprovincialis pediveligers assayed settled on biofilmed glass slides, while none settled on unfilmed slides. Likewise, in a chemotactic laboratory experiment, $>50 \%$ of $M$. edulis pediveligers (250 to $300 \mu \mathrm{m}$ ) moved towards biofilm scraped from the alga Cladophora rupestris (Dobretsov 1999), not only indicating an attraction to biofilm, but also that the cue was waterbourne. Wainman et al. (1996) found significant attraction of Dreissena polymorpha settlers $(<390 \mu \mathrm{m})$ to both biofilm and adult conspecifics.

Although Wainman et al. (1996) quoted a reduction in settlement of Dreissena polymorpha of 10 to $20 \%$ in treatments without biofilm, calculation of enhancement values from their data (using Eq. 1) indicates a 2-fold increase in mean settlement from that on bare stone to that on stone with biofilm and a 4 -fold increase from that on bare stone to that on conspecific adults with biofilm. These percentages compare well with the present findings (a 3.8-fold increase for primary Perna settlement in the B treatment and a 6.6-fold increase for secondary Perna settlers in the BS treatment).

Comparable support for conspecific attraction in marine mussels also exists, with Dobretsov \& Wahl (2001) showing a 2-fold increase in settlement of Mytilus edulis on artificial substrata placed in close proximity to adult beds, relative to controls. As with biofilm, detection of waterborne conspecific cues by adult $M$. edulis results in a significant increase in movement towards the source (de Vooys 2003). Interestingly, the similar degree of conspecific attraction found in these studies (which investigated attraction to adults, e.g. Wainman et al. 1996, Dobretsov \& Wahl 2001) and the present study mean that juvenile mussels have approximately the same attractant effect as adults.

\section{Methodological and ecological implications}

Findings presented here are of practical importance to studies making use of artificial substrata to explore settlement dynamics, particularly when using serialreplacement techniques. Such techniques require that experimental substrata be deployed, removed and replaced with bare substrata. Bare substrata effectively 're-set' the colonisation process, not only of biofilm but also of settling larvae. As first noted by Hrs-Brenko (1973), this 're-setting' may explain unnaturally low settlement on serially replaced substrata. Similarly, the influence of biofilm on settlement may also be relevant to experimental methods using or comparing established and cleared plots, particularly where heat sterilisation of substrata is used. The enhancement factors calculated from our results demonstrate that the effects of biofilm and conspecifics on settlement could possibly be accounted for using a posteriori numerical corrections, although artificial colonisation of experimental substrata prior to deployment may provide an alternative.

More important is the ecological imperative to understand small-scale settlement behaviour and its ecological consequences. Although subject to post-settlement processes, settlement patterns determined by larval behaviour and habitat (substratum) selection, such as those recorded in our experiments, have the potential to act as the 'starting' point of population structure. This is because patterns established at settlement can propagate through the juvenile and adult stages (e.g. Johnson \& Geller 2006). In this sense, small-scale habitat selection potentially determines local population distribution, structure and dynamics. Although the relevance of localised processes to regional or metapopulation ecology is debatable, empirical support for the influence of small-scale settlement behaviour on metre- and geographical-scale 
ecological processes does exist (Strathmann et al. 1981, Berntsson et al. 2004).

Finally, mussel and macroalgal beds have been interpreted as alternative stable states of the same ecosystem (Petraitis \& Dudgeon 2004). Field studies of unexploited Perna perna populations indicate that as many as two-thirds of recruits of $<1 \mathrm{~mm}$ in size are found on algae (McQuaid \& Lindsay 2005), possibly reflecting the conspecific avoidance shown in the current study. A consequence is that, where mussels have been eliminated by overexploitation and replaced by algae on whole-shore scales (e.g. Lasiak 1991), virtually all settlement will occur on macroalgae. There is evidence that growing recruits are unable to relocate from an initial algal settlement site to adult beds (Erlandsson et al. 2008). In this case, reluctance of larvae to settle among adult conspecifics, as suggested by primary settler preferences identified in the present study, will form a mechanism that provides stability to the algal state by inhibiting reversion to the mussel state. Increased understanding of settlement behaviour, including fine-scale ontogenetic resolution, may, therefore, help to resolve natural patterns such as these and will allow for new hypotheses concerning the extent to which small-scale settlement patterns influence larger-scale ecological processes.

Acknowledgements. This work is based upon research supported by the South African Research Chairs Initiative of the Department of Science and Technology and National Research Foundation. The authors are indebted to Dr Victoria Cole for her incisive advice through all stages of the work. Thanks also go to MCM (Marine \& Coastal Management) and the National Research Foundation for funding C. E. O. von der Meden.

\section{LITERATURE CITED}

Azam F, Fenchel T, Field JG, Gray JS, Meyer-Reil LA, Thingstad F (1983) The ecological role of water-column microbes in the sea. Mar Ecol Prog Ser 10:257-263

Bao WY, Yang JL, Satuito CG, Kitamura H (2007) Larval metamorphosis of the mussel Mytilus galloprovincialis in response to Alteromonas sp. 1: evidence for two chemical cues? Mar Biol 152:657-666

Bayne BL (1964) The responses of the larvae of Mytilus edulis L. to light and to gravity. Oikos 15:162-174

Berntsson KM, Jonsson PR, Larsson AI, Holdt S (2004) Rejection of unsuitable substrata as a potential driver of aggregated settlement in the barnacle Balanus improvisus. Mar Ecol Prog Ser 275:199-210

Bertness MD, Grosholz E (1985) Population dynamics of the ribbed mussel, Geukensia demissa: the costs and benefits of an aggregated distribution. Oecologia 67:192-204

Bownes S (2005) Habitat segregation in competing species of intertidal mussels in South Africa. PhD thesis, Rhodes University, Grahamstown

Bownes S, Barker NP, McQuaid CD (2008) Morphological identification of primary settlers and post-larvae of three mussel species from the coast of South Africa. Afr J Mar Sci 30:233-240

Chia FS, Koss R (1988) Induction of settlement and metamorphosis of the veliger larvae of the nudibranch, Onchidoris bilamellata. Int J Invert Reprod Devel 14:53-70

Clare AS, Freet RK, McClary M (1994) On the antennular secretion of the cyprid of Balanus amphitrite amphitrite, and its role as a settlement pheromone. J Mar Biol Assoc UK 74:243-250

Crisp DJ, Ryland JS (1960) Influence of filming and of surface texture on the settlement of marine organisms. Nature 185:119

> Davis AR, Moreno CA (1995) Selection of substrata by juvenile Choromytilus chorus (Mytilidae): Are chemical cues important? J Exp Mar Biol Ecol 191:167-180

> Day RW, Williams MC, Hawkes GP (1995) A comparison of fluorochromes for marking abalone shells. Mar Freshw Res 46:599-605

de Vooys CGN (2003) Effect of a tripeptide on the aggregational behaviour of the blue mussel Mytilus edulis. Mar Biol 142:1119-1123

> Dobretsov SV (1999) Effects of macroalgae and biofilm on settlement of blue mussel (Mytilus edulis L.) larvae. Biofouling 14:153-165

Dobretsov S, Wahl M (2001) Recruitment preferences of blue mussel spat (Mytilus edulis) for different substrata and microhabitats in the White Sea (Russia). Hydrobiologia 445:27-35

Dobretsov S, Wahl M (2008) Larval recruitment of the blue mussel Mytilus edulis: the effect of flow and algae. J Exp Mar Biol Ecol 355:137-144

> Dobretsov S, Dahms H, Qian P (2006) Inhibition of biofouling by marine microorganisms and their metabolites. Biofouling 22:43-54

Eads CB, Layzer JB (2002) How to pick your mussels out of a crowd: using fluoresence to mark juvenile freshwater mussels. J N Am Benthol Soc 21:476-486

Erlandsson J, Porri F, McQuaid CD (2008) Ontogenetic changes in small-scale movement by recruits of an exploited mussel: implications for the fate of larvae settling on algae. Mar Biol 153:365-373

- Eyster LS, Pechenik JA (1988) Attachment of Mytilus edulis L. larvae on algal and byssal filaments is enhanced by water agitation. J Exp Mar Biol Ecol 114:99-110

Hadfield MG (1986) Settlement and recruitment of marine invertebrates: a perspective and some proposals. Bull Mar Sci 39:418-425

Harder T, Lau SCK, Dahms HU, Qian PY (2002) Isolation of bacterial metabolites as natural inducers for larval settlement in the marine polychaete Hydroides elegans (Haswell). J Chem Ecol 28:2029-2043

Hidu H (1969) Gregarious setting in the American oyster Crassostrea virginica Gmelin. Chesap Sci 10:85-92

> Hrs-Brenko M (1973) The study of mussel larvae and their settlement in Vela Draga Bay (Pula, the northern Adriatic Sea). Aquaculture 2:173-182

Huxham M, Richards M (2003) Can post-larval bivalves select sediment type during settlement? A field test with Macoma balthica (L.) Cerastoderma edule (L.). J Exp Mar Biol Ecol 288:279-293

Johnson SB, Geller JB (2006) Larval settlement can explain the adult distribution of Mytilus californianus Conrad but not of M. galloprovincialis Lamarck or M. trossulus Gould in Moss Landing, central California: evidence from genetic identification of spat. J Exp Mar Biol Ecol 328: 136-145

> Kaehler S, McQuaid CD (1999) Use of the fluorochrome calcein as an in situ growth marker of the brown mussel Perna perna. Mar Biol 133:455-460 
Kavouras JH, Maki JS (2003) Effects of biofilms on zebra mussel postveliger attachment to artificial surfaces. Invertebr Biol 122:138-151

Keough MJ, Raimondi PT (1995) Responses of settling invertebrate larvae to bioorganic films - effects of different types of films. J Exp Mar Biol Ecol 185:235-253

Kobak J (2001) Light, gravity and conspecifics as cues to site selection and attachment behaviour of juvenile and adult Dreissena polymorpha Pallas, 1771. J Molluscan Stud 67: 183-189

Lasiak T (1991) The susceptibility and/or resilience of rocky littoral molluscs to stock depletion by the indigenous coastal people of Transkei, southern Africa. Biol Conserv 56:245-264

Lehane C, Davenport J (2004) Ingestion of bivalve larvae by Mytilus edulis: experimental and field demonstrations of larviphagy in farmed blue mussels. Mar Biol 145:101-107

Maki JS, Rittschof D, Schmidt AR, Snyder AG, Mitchell R (1989) Factors controlling attachment of bryozoan larvae-a comparison of bacterial films and unfilmed surfaces. Biol Bull 177:295-302

Mapstone BD, Underwood AJ, Creese RG (1984) Experimental analyses of the commensal relation between intertidal gastropods Patelloida mufria and the trochid Austrocochlea constricta. Mar Ecol Prog Ser 17:85-100

Marsden JR (1991) Responses of planktonic larvae of the serpulid polychaete Spirobranchus polycerus var. augeneri to an alga, adult tubes and conspecific larvae. Mar Ecol Prog Ser 71:245-251

Marshall DJ, Keough MJ (2003) Variation in the dispersal potential of non-feeding invertebrate larvae: the desperate larva hypothesis and larval size. Mar Ecol Prog Ser 255:145-153

> McQuaid CD, Lindsay JR (2005) Interacting effects of wave exposure, tidal height and substratum on spatial variation in densities of mussel Perna perna plantigrades. Mar Ecol Prog Ser 301:173-184

Meadows PS, Campbell JI (1972) Habitat selection by aquatic organisms. Adv Mar Biol 10:271-382

Moran AL (2000) Calcein as a marker in experimental studies of newly-hatched gastropods. Mar Biol 137:893-898

Nielsen KJ, Franz DR (1995) The influence of adult conspecifics and shore level on recruitment of the ribbed mussel Geukensia emissa (Dillwyn). J Exp Mar Biol Ecol 188: 89-98

> Olson MH (1996) Ontogenetic niche shifts in largemouth bass: variability and consequences for first-year growth. Ecology 77:179-190

Pawlik JR (1986) Chemical induction of larval settlement and metamorphosis in the reef-building tube worm Phragmatopoma californica (Sabellariidae: Polychaeta). Mar Biol 91:59-68

Pawlik JR (1992) Chemical ecology of the settlement of benthic marine invertebrates. Oceanogr Mar Biol Annu Rev 30:273-335

> Pernet F, Tremblay R, Bourget E (2003) Settlement success, spatial pattern and behavior of mussel larvae Mytilus spp. in experimental 'downwelling' systems of varying velocity and turbulence. Mar Ecol Prog Ser 260:125-140

Petersen JH (1984) Larval settlement behaviour in competing species: Mytilus californianus Conrad and M. edulis L. J Exp Mar Biol Ecol 82:147-159

Petraitis PS, Dudgeon SR (2004) Detection of alterative stable states in marine communities. J Exp Mar Biol Ecol 300: $343-371$
Porri F, Zardi GI, McQuaid CD, Radloff S (2007) Tidal height, rather than habitat selection for conspecifics, controls settlement in mussels. Mar Biol 152:631-637

Porri F, Jordaan T, McQuaid CD (2008) Does cannibalism of larvae by adults affect settlement and connectivity of mussel populations? Estuar Coast Shelf Sci 79:687-693

Qian PY (1999) Larval settlement of polychaetes. Hydrobiologia 402:239-253

$>$ Rodríguez SR, Ojeda FP, Inestrosa NC (1993) Settlement of benthic marine invertebrates. Mar Ecol Prog Ser 97: 193-207

Satuito CG, Natoyama K, Yamazaki M, Fusetani N (1994) Larval development of the mussel Mytilus edulis galloprovincialis cultured under laboratory conditions. Fish Sci 60: 65-68

Satuito CG, Natoyama K, Yamazaki M, Fusetani N (1995) Induction of attachment and metamorphosis of laboratory cultured mussel Mytilus edulis galloprovincialis larvae by biofilm. Fish Sci 61:223-227

> Satuito CG, Shimizu K, Fusetani N (1997) Studies on the factors influencing larval settlement in Balanus amphitrite and Mytilus galloprovincialis. Hydrobiologia 358: $275-280$

Smith DA, Rule MJ (2002) Artificial substrata in a shallow sublittoral habitat: Do they adequately represent natural habitats or the local species pool? J Exp Mar Biol Ecol 277: $25-41$

Strathmann RR, Branscomb ES, Vedder K (1981) Fatal errors in set as a cost of dispersal and the influence of intertidal flora on set of barnacles. Oecologia 48:13-18

Svane I, Dolmer P (1995) Perception of light at settlement: a comparative study of two invertebrate larvae, a scyphozoan planula and a simple ascidian tadpole. J Exp Mar Biol Ecol 187:51-61

Thompson RC, Tobin ML, Hawkins SJ, Norton TA (1999) Problems in extraction and spectrophotometric determination of chlorophyll from epilithic microbial biofilms: towards a standard method. J Mar Biol Assoc UK 79: $551-558$

Underwood AJ (1997) Ecological experiments: their logical design and interpretation using analysis of variance. Cambridge University Press, Melbourne

Uryu Y, Iwasaki K, Hinoue M (1996) Laboratory experiments on the behaviour and movement of a freshwater mussel, Limnoperna fortunei (Dunker). J Molluscan Stud 52: 327-341

Wainman BC, Hincks SS, Kaushik NK, Mackie GL (1996) Biofilm and substrate preference in the dreissenid larvae of Lake Erie. Can J Fish Aquat Sci 53:134-140

Werner EE, Hall DJ (1988) Ontogenetic habitat shifts in bluegill: the foraging rate-predation risk trade-off. Ecology 69:1352-1366

Wieczorek SK, Todd CD (1998) Inhibition and facilitation of settlement of epifaunal marine invertebrate larvae by microbial biofilm cues. Biofouling 12:81-118

Wilson DP (1968) The settlement behaviour of the larvae of Sabellaria alveolata (L.). J Mar Biol Assoc UK 48:387-435

Zar JH (1999) Biostatistical analysis, 4th edn. Prentice-Hall, Englewood Cliffs, NJ

Zhao B, Qian PY (2002) Larval settlement and metamorphosis in the slipper limpet Crepidula onyx (Sowerby) in response to conspecific cues and the cues from biofilm. J Exp Mar Biol Ecol 269:39-51

Zobell CE, Allen EC (1935) The significance of marine bacteria in the fouling of submerged surfaces. J Bacteriol 29: 230-251 